\title{
Employment policy and autism: Analysis of state Workforce Innovation and Opportunity Act (WIOA) implementation plans
}

\author{
Anne M. Roux*, Tamara Garfield and Paul T. Shattuck \\ A.J. Drexel Autism Institute, Drexel University, Philadelphia, PA, USA
}

Revised/Accepted March 2019

\begin{abstract}
.
BACKGROUND: The problem of persistently low rates of employment and earnings for people with autism is well established. In the U.S., the 2014 Workforce Innovation and Opportunity Act (WIOA) updated the legal framework for the federal Vocational Rehabilitation (VR) program which assists people with disabilities to find and maintain employment.

OBJECTIVE: This study examined whether and how the needs of transition-age youth and adults with autism are addressed in state WIOA plans.

METHODS: We analyzed WIOA documents for all states plus the District of Columbia using content analysis.

RESULTS: Of the 51 state plans, 44 contained references to autism, and 19 explicitly identified autism as a disability group that is underserved by the state VR agency. Even among states that clearly defined autism as underserved, only 10 provided comprehensive plans which defined goals and strategies to address the vocational needs of this group. We discuss major themes related to VR service delivery for people with autism identified within the state plans.

CONCLUSIONS: This study identifies state policy aimed at facilitating employment for people with autism and contributes to efforts to discover why individuals with autism in some states have better employment outcomes than in others.

Keywords: Autism spectrum disorder (ASD), Vocational Rehabilitation (VR), Workforce Innovation and Opportunity Act (WIOA), transition, policy, law/legal issues
\end{abstract}

\section{Background}

The problem of persistently low rates of employment and earnings for people with autism spectrum disorder (ASD) is well established (Howlin \& Moss, 2012; Magiati, Tay, \& Howlin, 2014; Shattuck, Roux, et al., 2012). Only one in five working-age individuals on the spectrum has a "good" overall outcome, defined as generally able to work but requiring supports for daily living (Steinhausen, Mohr Jensen, \& Lauritsen, 2016), and at least half of adults with ASD

*Address for correspondence: Anne M. Roux, M.A., M.P.H., A.J. Drexel Autism Institute, Drexel University, 3020 Market St., Suite 560, Philadelphia, PA 19130, USA. Tel.: +1 267788 9762; E-mail: amr376@drexel.edu. require significant supports for employment (Magiati et al., 2014).

In the U.S., the Vocational Rehabilitation (VR) program is designed to assist people with disabilities who need support to find and maintain employment. In federal fiscal year (FFY) 2015 nearly 18,000 VR cases of youth and adults with ASD closed - doubling the 9,000 cases closed in FFY 2010 (Roux, Rast, Anderson, \& Shattuck, 2016). Nationally, about $50-60 \%$ of transition-age youth (TAY) and adults on the autism spectrum attain employment following VR services (Kaya et al., 2016; Roux et al., 2016; Roux, Rast, \& Shattuck, 2018), most working part-time at low wages (Roux et al., 2016), and often earning less than their peers with other types of disabilities (Burgess \& Cimera, 2014). 
Dramatic differences exist across states in distribution of VR service use and related outcomes for people with ASD (Burgess \& Cimera, 2014; Migliore, Butterworth, \& Zalewska, 2014; Roux, Rast, \& Shattuck, 2018). Analysis of VR data for FFY 2014-2016 revealed 30 to 60 percentage point spreads across states for service receipt, early reach, timely services, and employment at VR exit among transition-age youth with ASD (TAY-ASD) who were eligible for VR services (Roux, Rast, NyeLengerman, et al., 2018). State-level variation in VR outcomes for those with ASD is not adequately explained by models that consider demographics and impairment characteristics of service users (Kaya et al., 2016), or by models that also include state unemployment rates or funds a state might have available for social services (Roux, Rast, \& Shattuck, 2018). This suggests that other, unidentified factors may be influential. The structure of VR programs, availability of services, eligibility criteria, prioritization of who receives services, and funding can differ considerably by state (Mann \& Croake, 2018). Studying state-level differences in VR policies and practices could offer additional insight into what contributes to better performance in some states.

\subsection{Vocational services and autism}

The employment support needs of people with ASD merit special attention because of the social-cognitive, behavioral, and communication impairments associated with ASD (Hendricks, 2010; Müller, Schuler, Burton, \& Yates, 2003; Richards, 2012), in addition to the frequent co-occurrence of health and mental health diagnoses (Croen et al., 2015). These issues contribute to a complex array of employment challenges mixed with potential strengths in memory, focus, and in-depth knowledge of special interest areas (Hurlbutt \& Chalmers, 2004; Müller et al., 2003; Richards, 2012). Ongoing access to job coaching or mental health supports after a job is obtained may be necessary to meet the unique needs of this population, but VR does not typically provide these services (U.S. Government Accountability Office, November 17, 2016). Vocational interventions for ASD have traditionally focused on modifying individuals' impairments versus modifying policies, practices or work environments, and have thus yielded little evidence of improvement in actual employment rates (Scott et al., 2018).
The context surrounding vocational service delivery has also shifted in recent years. Rates of employment within the general population declined dramatically during and following the Great Recession, making employment opportunities scarce for people with disabilities (Livermore \& Honeycutt, 2015). A simultaneous shift to a knowledge-based economy required workers with more postsecondary training (Bird, Foster, \& Ganzglass, 2014), while job creation shifted toward the service sector where many jobs revolve around a core need to successfully interact and communicate with others. These changes pose unique challenges for adults on the spectrum who tend to have social impairments (American Psychiatric Association, 2013) and low rates of postsecondary education (Shattuck, Narendorf, et al., 2012; Wei, Yu, Shattuck, McCracken, \& Blackorby, 2013).

Some consensus regarding priorities for improving employment services for individuals with ASD is emerging. The federal Interagency Autism Coordinating Committee (IACC) Strategic Plan recommended "expanding current models of job finding and development services, long-term intensive services and supports, and long-term but minimal supports (e.g., a few hours/month)," (IACC, October 2017) along with better training of employment support providers. Other federal panels have called for development of more direct support providers with competency to serve those with autism (U.S. Government Accountability Office, November 17, 2016).

\subsection{WIOA and Vocational Rehabilitation}

As of 2017, each state has a unique, federally approved plan for implementing the 2014 Workforce Innovation and Opportunity Act (WIOA) legislation which updated the legal framework for the VR program. WIOA seeks to "increase access to and opportunities for the employment, education, training, and support services that individuals, particularly those with barriers to employment, need to succeed in the labor market," and to "promote improvement in the structure and delivery of services" (U.S. Department of Labor, March 4, 2016). Major changes within WIOA included limitations on subminimum wages and a new requirement that states spend $15 \%$ of their VR funds on pre-employment transition services (Pre-ETS) for students with disabilities.

Each state WIOA plan summarizes rehabilitation needs within the state and identifies populations which have been unserved or underserved by VR, including youth and students with disabilities and 
their need for transition services and Pre-ETS (34 CFR \$361.29). Underserved groups are those who have not traditionally received equal access to and benefits from rehabilitation services (e.g., racial and ethnic minorities), but may also include specific disability groups (The VR Needs Assessment Guide, November 30, 2009). By design, state WIOA plans should specify strategies for outreach to underserved groups, methods to expand and improve services, and details regarding how the state will support innovation and expansion (I\&E) services and overcome barriers related to access. Per WIOA state plan instructions, "While discussion of strategies for every target population is not expected, States must address as many as are applicable to their State's population and look beyond strategies for the general population." Youth and adults with ASD are an example of a group that may require tailored strategies to improve their employment outcomes. In fact, the IACC Strategic Plan (October 2017) pointed to the need to study autism-related state initiatives emerging from WIOA. To our knowledge, the content of state WIOA plans has not been systematically analyzed to understand whether and how states are specifically attempting to address the needs of youth and adults on the autism spectrum.

\subsection{Purpose of this study}

We analyzed state WIOA plans with the following aims: (1) Characterize the prevalence and types of autism-specific references across state WIOA plans, and the degree to which youth and adults with autism are identified as an underserved group, (2) Describe the goals, strategies and programs states propose to improve VR services for youth and adults with autism.

\section{Methods}

Document analysis involves identifying, appraising, and synthesizing data from documents of interest (Bowen, 2009). We analyzed WIOA FFY 2016 Unified and Combined State Plans for all 50 states and the District of Columbia published at rsa.ed.gov, including the portions of plans that discussed VR services for the blind when applicable. This study was deemed exempt by the Drexel University Institutional Review Board.

All 51 plans were uploaded to NVivo qualitative analysis software. The lead author and a doctoral stu- dent assistant reviewed the structure of state plans and identified sections that contained information on autism using a query on the truncated key word "autis*." The lead author then pre-identified text segments containing autism references for analysis. We excluded references to autism that were public comments from state needs assessments.

We used qualitative content analysis to examine our research questions and to identify manifest (visible structure) and latent (deeper meaning) themes within the state plan autism references (Schreier, 2012). We used plan subsection headings to develop a set of a priori codes for topics (e.g., statewide needs assessment) and then coded subthemes (e.g, underserved, transition, training and technical assistance). We conducted trial coding using the WIOA plans from three U.S. territories not included in this analysis and used the results to refine and organize codes. The two raters then independently coded two plans. The lead author calculated inter-rater agreement (IRA) by dividing the number of codes with agreement by the total number of possible codes (agree + disagree) multiplied by 100 . We discussed, revised and defined codes until we reached an IRA of $88 \%$ on an additional set of test plans. We then coded all remaining plans independently, compared codes, and discussed discrepancies until agreement was reached for each plan (Barbour, 2014). Throughout the coding process, both raters kept a running log with detailed notes and insights. Below, we define several key terms.

We coded autism as an underserved group if autism was referred to in the section of the state plan that discussed the needs of currently underserved groups, or if there was a reference to autism being underserved within the goals/priorities or state strategies sections. We did not include indirect mentions such as "underserved youth" even if they co-occurred with a reference to autism. Identification of underserved groups should be based on findings from the periodic Comprehensive State Needs Assessment (CSNA) of rehabilitation needs.

We defined autism-specific services and programs as those designed to meet the needs of people with autism or that specifically included people with autism as a target population. We only included services or programs whose existence was verifiable through an internet search or documentation on the state VR agency's website. We also excluded programs if we were unable to verify that they included autism as a target service population.

Finally, we defined plans as comprehensive in addressing the needs of VR service users with autism 
if they: 1) identified autism as an underserved group, 2) delineated strategies for addressing the vocational needs of those with autism, and 3) specifically connected these strategies to a defined goal.

\section{Results}

Of the 51 state plans analyzed in this study, 44 (86\%) made direct references to autism, while seven contained no mention of autism (Fig. 1). Thirteen states noted a significant increase in the number and/or proportion of autism cases in VR caseloads (AL, IL, KS, KY, MD, ME, MI, NE, NY, SC, TX, VA, WA). Virginia's VR autism cases increased from 1,339 served in 2010 to 3,086 in 2015 (131\%), and South Carolina estimated that 7,000-7,500 of its youth (ages 16-25) have autism. Autism was the "largest growing special education population" in Washington, but VR "currently serves less than three percent of potentially eligible students with disabilities statewide," including those with autism.

Nineteen states (37\%) identified people with autism as a currently underserved group (Fig. 1, Column A), some specifically naming "high-functioning adults living with an autism spectrum disorder" (WA) and students and youth with autism (MI, TX) as underserved. Although not specific to autism, Indiana noted, "Students with milder disabilities are often seen as not being eligible for VR services and are thus underserved." However, the determination of "underserved" groups also varied across states. Maryland calculated the number of providers in a region versus prevalence of autism, while Missouri reviewed research and publications to determine that autism was underserved.

Twenty-five states (49\%) included strategies that specifically referenced autism $(n=19)$, or defined goals or objectives that named people with autism as a target population ( $n=6$ ) (Fig. 1, Column B). Goals primarily targeted improving employment outcomes and increasing competitive, integrated employment for people with autism. DC set a goal for training and recruiting VR staff and service providers to serve "low incidence populations" including autism.

Twenty-seven states (53\%) identified a need for autism-specific training and/or currently provided autism training of some type (Fig. 1, Column C). Trainings targeted VR counselors - new and experienced, VR autism specialists, community rehabilitation providers (CRPs), business service teams, partners at the Department of Disability Services, Workforce \& Technology center staff, and vocational evaluators. Most states used a train-the-trainer model to build a competent workforce to serve VR consumers with ASD. North Dakota collaborated with its Medicaid Autism Unit to train VR staff. Seven states utilized designated "ASD specialists" or subject matter experts (SMEs) (Fig. 1, Column D), but only Texas included information on training required for specialists.

Twenty-three states (45\%) documented collaboration across agencies and organizations to improve VR autism services (Fig. 1, Column E). Most forged interagency partnerships to design and execute autism programs and services. Others collaborated to identify and provide for transition-related needs $(\mathrm{CO}$, IL, KY), conduct outreach (GA), develop requirements for service providers (MO), improve referral processes (MO), identify individuals who might benefit from the state's autism waiver (ND), and meet with advocacy groups to identify resources (TN). Three states mentioned Project SEARCH specific collaborations (DE, MI, NH). Nevertheless, the depth or quality of collaborative efforts was difficult to evaluate, and there was almost no mention across plans of how community stakeholders and advocacy groups informed goals or strategies, or how they were involved in collaborative efforts.

Nine states had VR agency representation on state councils or committees that advise on matters specifically related to autism (CO, KS, KY, MI, MN, $\mathrm{NE}, \mathrm{NH}, \mathrm{NV}, \mathrm{PA}$ ). For example, Colorado's VR agency participated on the Colorado Ad Hoc Autism Group to "promote better coordination of services and shared resources at both the state and local levels." VR collaborated with a statewide advisory group to address transition needs of TAY-ASD in six of these states.

Overall, we identified 10 states (20\%) with "comprehensive" plans for addressing needs of those with autism (Table 1). While all had autism-specific strategies, only four tied these strategies to autismspecific goals. Others used generic, overarching goals that encompassed strategies for serving those with autism.

\subsection{Autism-specific VR services}

Twelve plans (24\%) described autism-specific services and programs (Table 2). Some of these programs were limited to specific locales, and several were pilot programs. In contrast, Virginia's 


\begin{tabular}{|c|c|c|c|c|c|}
\hline State & $\begin{array}{l}\text { ASD is } \\
\text { underserved } \\
\text { by the state } \\
\text { VR agency }\end{array}$ & $\begin{array}{l}\underline{B} \\
\text { ASD is directly } \\
\text { addressed in a goal/ } \\
\text { priority }(G) \text {, strategy } \\
\text { (S), or both }(G+S)\end{array}$ & $\begin{array}{l}\text { State } \underline{\mathrm{CR}} \text { needs } \\
\text { or is currently } \\
\text { delivering } \\
\text { autism training }\end{array}$ & $\begin{array}{c}\underline{D} \\
\text { Use of } \\
\text { ASD } \\
\text { specialists }\end{array}$ & $\begin{array}{c}\underline{E} \\
\text { ASD-related } \\
\text { interagency } \\
\text { partnerships }\end{array}$ \\
\hline Alabama & $\bullet$ & $\mathrm{S}$ & $\bullet$ & & $\bullet$ \\
\hline Alaska & & & $\bullet$ & & \\
\hline Arkansas & & & - & & \\
\hline California & & & & & $\bullet$ \\
\hline Colorado & & & & & $\bullet$ \\
\hline Connecticut & $\bullet$ & $\mathrm{G}+\mathrm{S}$ & $\bullet$ & & \\
\hline Delaware & & & & & $\bullet$ \\
\hline Dist. of Columbia & & G & $\bullet$ & & \\
\hline \multicolumn{6}{|l|}{ Florida } \\
\hline Georgia & $\bullet$ & $\mathrm{G}+\mathrm{S}$ & $\bullet$ & - & - \\
\hline Illinois & $\bullet$ & & & & $\bullet$ \\
\hline Indiana & $\bullet$ & & & & \\
\hline lowa & & & $\bullet$ & & \\
\hline Kansas & - & $S$ & - & & \\
\hline Kentucky & $\bullet$ & $S$ & $\bullet$ & & $\bullet$ \\
\hline Louisiana & & $S$ & & & $\bullet$ \\
\hline \multicolumn{6}{|l|}{ Maine } \\
\hline Maryland & $\bullet$ & $\mathrm{S}$ & $\bullet$ & $\bullet$ & $\bullet$ \\
\hline Massachusetts & & G & & & \\
\hline Michigan & $\bullet$ & $\mathrm{S}$ & $\bullet$ & & - \\
\hline Minnesota & & & & $\bullet$ & \\
\hline Mississippi & & & $\bullet$ & & \\
\hline Missouri & $\bullet$ & $\mathrm{S}$ & $\bullet$ & $\bullet$ & $\bullet$ \\
\hline Montana & & $\mathrm{S}$ & - & & \\
\hline Nebraska & $\bullet$ & & $\bullet$ & & $\bullet$ \\
\hline Nevada & $\bullet$ & $\mathrm{S}$ & & & - \\
\hline New Hampshire & & $S$ & $\bullet$ & & $\bullet$ \\
\hline \multicolumn{6}{|l|}{ New Jersey } \\
\hline New York & - & $\mathrm{S}$ & - & & - \\
\hline North Carolina & - & & $\bullet$ & & \\
\hline North Dakota & & & $\bullet$ & & $\bullet$ \\
\hline Oklahoma & & & $\bullet$ & & $\bullet$ \\
\hline Oregon & & & $\bullet$ & - & \\
\hline Pennsylvania & & & & & $\bullet$ \\
\hline Rhode Island & & $S$ & - & & \\
\hline South Carolina & & $\mathrm{S}$ & - & & • \\
\hline South Dakota & & & $\bullet$ & & \\
\hline Tennessee & $\bullet$ & $\mathrm{S}$ & $\bullet$ & & $\bullet$ \\
\hline Texas & - & $G+S$ & - & - & • \\
\hline Utah & - & & & & \\
\hline \multicolumn{6}{|l|}{ Vermont } \\
\hline Virginia & $\bullet$ & $S$ & $\bullet$ & $\bullet$ & - \\
\hline Washington & $\bullet$ & $\mathrm{S}$ & & & - \\
\hline Wisconsin & & & & & \\
\hline
\end{tabular}

Fig. 1. Key types of autism-specific references within state WIOA plans for VR services. Note: Figure represents states with references to autism in their WIOA state plan. Source: 2016 WIOA state plans.

program was "designed to be planned and delivered as part of a coordinated continuum of services model" for VR consumers with autism. Some states focused on modifying and expanding existing services to better meet the needs of those with autism including job placement (AL, KY, MO, NC), work- 
Table 1

Example activities of states with comprehensive plans for meeting the needs of VR service users with autism

\begin{tabular}{ll}
\hline State & Focus of Goal/ Priority \\
\hline AL & "Increase case service dollars expended for \\
& Supported Employment by 5\%" \\
CT & "Increase employment outcomes for individuals \\
& with disabilities, particularly those individuals \\
& from unserved or underserved populations"
\end{tabular}

GA

"Increase and improve competitive employment outcomes and career opportunities for unserved and underserved populations, to include... autism"

KY "Provide Pre-employment transition services (Pre-ETS) to transition Students (ages 14-21) and other transition services to Youth (ages 16-24)..."

“... enhance integration of vocational rehabilitation and supported employment services to individuals with disabilities..."

MO

"Increase competitive integrated employment outcomes for individuals with autism spectrum disorder"

NY "Increase services to target populations: students with disabilities; and unserved and underserved groups"

TX "Improve consumer employment outcomes for individuals with significant disabilities to include... autism"

VA

"Identify best practices, create strategies, and partner with other agencies to better serve students and youth with disabilities..."

WA "Conduct outreach to key populations, including students and out-of-school youth with disabilities"
Strategies

- Expand the Connections program to individuals with autism in secondary schools to increase successful postsecondary employment outcomes

- "Hold three meetings of the Autism Spectrum Disorder (ASD) Committee to develop more responsive services for individuals with autism spectrum disorders."

- "Provide joint staff training for BRS and Department of Developmental Services (DDS) staff on Autism Services."

- "Recruit and hire internal subject-matter experts to better serve the unserved and underserved populations, such as ... those with Autism."

- "Offer unique services to special populations, such as individuals on the Autism Spectrum. GVRA will do this by identifying specific population needs statewide, identifying and developing services to address these needs, and collaborating with both current and potential new providers to develop new services addressing these needs."

- "Coordinate with the Autism Council/Office of Autism to discuss and address the issues of students with autism"

- Support a summer transitions program specifically designed for high school rising juniors and rising seniors who have been diagnosed on the Autism Spectrum who have expressed an interest in transitioning into higher education

- "Continue strategic activities that will enhance DORS [Division of Rehabilitation Services] capacity to meet the unique needs of individuals with autism spectrum disorders preparing for employment"

- "Increase the number of consumers with Autism served by DORS compared with the previous year (Performance measure)"

- "Coordinate joint training activities for ... counselors and direct services CRP staff to improve services and outcomes for clients with ASD"

- "Expand specialized employment services for individuals with ASD"

- "Add service options that will more specifically address the needs of those on the autism spectrum"

- "..provide training to program specialists and members of the Autism/Developmental Disorders Team"

- Continue to "review the need for revising the outcome-based payment method for supported employment and job placement to better serve... . Autism"

- "Provide VR counselors and their consumers with access to expert technical assistance and support for consumers with Intellectual Disabilities, brain injury, and Autism."

- Target equitable access to services and resources for underserved populations through... "new business partnerships which provide career pathways for highly skilled adults living with an autism spectrum disorder in Washington's technology industry."

Source: 2016 WIOA state plans.

place modifications (MO), job coaching (VA), and specialized training for STEM careers to better serve the autism group (WI). Maryland reported progress on adding Driver's Education services for individuals with autism.

Thirteen states described a current need for additional service options specific to the needs of individuals with autism (CT, GA, IL, MD, NH, NY, $\mathrm{TX}$ ) or long-term supported employment services for those with autism (CA, MN, MO, NC, NE, WI). Maryland listed "social support group, social skills training, and ADHD organizational training" as examples of needed services. New York was developing VR service options for "social speech and communication skill development."

Two state plans explicitly discussed using assistive technology (AT) services to meet the employment needs of VR service users with autism. Missouri described AT as including "assessment and recommendations for accommodations, assistive devices and assistive technology necessary to improve the quality of work and/or increase work productivity." Virginia provided loaner devices, coaching supports and webinars focused on AT, and included AT experts 
Table 2

Autism-specific services and programs identified in WIOA state plans

\begin{tabular}{|c|c|c|c|}
\hline State & Service/Program & Target population & Description \\
\hline$\overline{\mathrm{AL}}$ & Connections & $\begin{array}{l}\text { "Students and youth with social } \\
\text { skill deficits, especially those } \\
\text { with autism" }\end{array}$ & $\begin{array}{l}\text { Year-long classroom-based social skills program with } \\
\text { generalization of skills to real world community settings, } \\
\text { followed by referral to supported employment }\end{array}$ \\
\hline $\mathrm{CA}$ & College to Career (C2C) & $\begin{array}{l}\text { Students with intellectual } \\
\text { disability with or without ASD }\end{array}$ & $\begin{array}{l}\text { Cooperative program between Department of Rehabilitation } \\
\text { and five colleges to meet the needs of students with ID } \\
\text { and/or ASD in postsecondary education or the workforce }\end{array}$ \\
\hline $\begin{array}{l}\text { DE } \\
\text { MI } \\
\text { NH }\end{array}$ & Project SEARCH & $\begin{array}{l}\text { Transition-age youth, "in } \\
\text { particular youth with autism" }\end{array}$ & $\begin{array}{l}\text { Internship program for students in their last year of high } \\
\text { school. Students complete several unpaid internships } \\
\text { within integrated, competitive jobs within the community }\end{array}$ \\
\hline
\end{tabular}

DE Specialisterne - Computer Aid, Inc (CAI) partnership

DE Pathways to Employment

KY Autism summer transition program (Summer AutismOpen Doors College Experience)

MD Pathways

MO Employment Services Plus

\author{
NH AXIS \\ NH Family Centered Transition \\ Project
}

\section{NH Project INCOME \\ OK Autism Program \\ SC Workplace readiness training (service)}

TX Environmental Work Assessment

TX Autism Spectrum Disorder (ASD) Supports

VA Autism Speaks Comprehensive Assessment \& Service Program
Individuals on the autism spectrum

Low income youth (14-25 years) with a disability, including autism, "who have a desire to work in a competitive work environment"

High school rising juniors and rising seniors on the spectrum with an expressed "interest in transitioning into higher education"

Community college students on the autism spectrum

Individuals with autism and other impairments with "barriers that require additional supports to achieve a successful employment outcome."

Youth with autism

Youth with autism ages 16-24

Young adults who "experience high functioning Autism"

Transition-age students including with autism

Individuals with autism

People with autism

People with autism

Consumers with autism
Job training initially conducted by Specialisterne and then transferred to CAI who further trains individuals "for prescribed government and private contracts within deadlines for production."

Medicaid program* "designed to provide greater extended employment options via "individually tailored services." (*1915i Medicaid state plan amendment program)

Pre-ETS pilot program with Eastern Kentucky University

Provides support for community college students on the spectrum at several campuses via "enhanced case management" including "in-class personal assistance"

"ESP provides augmentative services for clients whose disability-related needs exceed the level of support provided by transition vocational rehabilitation services but does not merit consideration of SE [supported employment] services."

Pilot partnership between VR and a local area agency providing "life coaching toward employment"

Transition planning and training process for individuals and their families in partnership with the UNH Institute on Disability and Strafford Learning Center

Local training program for office skill development

Partnership between VR and Goodwill Tulsa with a "formal curriculum"

Partnership between VR and the Project HOPE Foundation using "individualized plans for Applied Behavioral Analysis (ABA) therapy conducted in a vocational preparation setting" to develop social skills and independent living skills, and to provide job coaching and placement into competitive employment (None)

(None)

High intensity comprehensive service pilots "providing direct services to VR consumers via a team-based model that includes designated autism subject matter experts (ASME), Assistive Technology Experts, and agency vendors of Supported Employment, Community Support Services, and Therapeutic Behavior Services"

Source: 2016 WIOA state plans. 
within their high-intensity comprehensive autism service pilot projects.

In regard to funding autism-related services, Nebraska used a Grants Management staff position to develop and implement innovative partnerships, including expansion of autism services and "development of a braided milestone funding payment system" to fund supported employment via a collaboration of VR, Health and Human Services, and the Division of Behavioral Health. Other states planned to use I\&E funds for specific current or future activities related including: training VR business service teams and providing a summer transition program (KY), expanding provision of services for autism (MD), funding lifespan services for individuals with autism delivered in partnership with a non-profit organization (SC), expanding Project SEARCH sites for TAY-ASD and to hire Autism SMEs (VA).

\subsection{Services for transition-age youth with autism}

Thirty state plans (59\%) referenced TAY-ASD. Five states reported delivering training activities regarding serving students and youth on the spectrum (AR, OK, SC, TX, VA), and two others reported a need for such trainings (KS, MI). Michigan stated, "Concern was expressed at all levels about the job readiness preparation this group will have as they exit school, the preparedness of the adult vocational rehabilitation agency staff to provide services, and the availability of supported employment services for this population." While not specific to autism, New Jersey also noted that "while many high schools take advantage of the [VR] counselor's expertise in vocational rehabilitation, others prefer not to include [VR] on a regular basis."

Of the 16 autism-specific services and programs listed in Table 2, nine (56\%) were directed at students or youth. Of these, Project SEARCH was the most prevalent transition program mentioned by name. At least two states discussed supports for students with autism seeking post-secondary education (MD, CA). Maryland designated VR staff to work collaboratively with community college Disability Support Services staff to provide supports including "one-on-one personal services, such as those required by students with autism spectrum disorders who could benefit from in-class assistance to maintain focus and attention or be reminded of classroom behaviors." Three states indicated a need for supported employment services for TAY-ASD (DC, LA, NE).
Kentucky was the only state that documented use of Pre-ETS for TAY-ASD, identifying the need to expand services and "coordinate with the Autism Council/Office of Autism to discuss and address the issues of students with Autism." Kentucky planned to support a summer program to facilitate transition into higher education. Other states discussed Pre-ETS in sections of the plans that referenced autism (ND, NE, NY, SC, TX), but it was unclear whether they planned to tailor Pre-ETS activities to meet the needs of students with autism.

\subsection{Engaging and educating employers}

Nine states referenced building relationships with employers to better meet the needs of the autism population (GA, KY, NC, NH, NY, TN, TX, VA, WA). Activities included educating employers on providing autism-friendly, culturally competent work environments; and educating employers on the benefits of hiring people with autism. New York stated it is important for "businesses to understand how this disability impacts on social roles as well as job task function.” Kentucky's VR agency provided autism training to Kentucky Career Center Business Service Teams who would then train employers. Georgia also mentioned use of the VR Business Division to develop employment opportunities with local employers for underserved populations like autism, and to "provide a variety of employer supports and services." Virginia and Washington developed specific business partnerships with the information technology industry.

\subsection{Building capacity}

Most state efforts to build capacity to serve people with autism involved training and technical assistance activities and creation of autism-specific services. Additionally, Alabama appointed a staff person in the VR state office "to develop and enhance the agency's autism program." Texas appointed a board-certified behavior analyst to serve as the State Program Specialist for Autism "to implement multiple strategies to enhance services" including an extensive training infrastructure for increasing staff competency. Texas also built capacity for job placement by identifying CRPs who had autism expertise and asking each to "develop at least one partnership with a business that has an autism-friendly work environment." Several states aimed to increase the capacity of CRPs (GA, LA, MD, NE, ND, RI) and/or competency of CRPs 
(AL, KS, MD, MI, MO, TX) to provide services to people with autism. In 2015, Texas implemented premium payments for CRPs "to reward providers who maintain training and skills necessary to work with specific populations," including autism. To earn the premium the CRP must show proof of specialized certification or licensure such as an Autism Specialization Certificate from the University at North Texas.

\subsection{Barriers to improving employment outcomes}

Twelve states named barriers to improving employment outcomes and/or providing VR services for those with autism (DC, DE, ME, MD, MI, MN, MO, NE, NC, SC, TN, TX). Barriers included: lack of staff training and expertise to serve those with autism $(n=3)$, inadequate resources for supporting individuals with multiple or complex disabilities (e.g., visual impairment and autism) $(n=3)$, lack of availability of supported employment for this population $(n=2)$, a lack of service providers to meet increasing demands $(n=2)$, and need for education of employers about hiring and accommodating people with autism $(n=2)$. Two states noted that individuals with autism who did not have ID did not qualify for long-term supported employment services through the state Developmental Disability (DD) agency via a Medicaid waiver. Tennessee also noted that "cultural competence in understanding various cultures and disabilities on the part of employers and some staff" is a barrier to reaching out to underserved groups including those with autism.

\section{Discussion}

This study analyzed FFY 2016 WIOA state plans with a focus on identifying how states propose to improve delivery of VR services for TAY and adults with autism. A general lack of state capacity to provide VR services for those with autism was evident in expressed concerns about the growing population of youth potentially needing vocational services and the identification of autism as an underserved group. This overall finding is consistent with other observations that states are lagging in their development of autism-specific policies and system capacity (Turcotte, Mathew, Shea, Brusilovskiy, \& Nonnemacher, 2016).

Twenty-one states, or nearly half of state plans that referenced autism, either described autismspecific services they were currently providing or documented a need to develop or adapt services for those with autism. Nineteen states had strategies explicitly aimed at improving employment for those with autism. However, about one-third of these did not anchor the strategies to a corresponding goal/priority. Even among states that clearly defined autism as an underserved disability group, only 10 plans were deemed comprehensive in nature, connecting goals and strategies to address the needs of this group. These findings are counter to guidance for evaluating state WIOA plans which asks whether the state plan includes a discussion of specific strategies to address the needs of individuals with disabilities who have barriers to employment (LEAD Center, February 2018).

Although the presence of clearly defined goals is a characteristic of states with higher performance in employment outcomes for people with ID and DD (Hall, Butterworth, Winsor, Gilmore, \& Metzel, 2007), discussion of autism-related needs and goals in WIOA plans often lacked specificity or featured excessive redundancy. South Carolina's plan, for example, repeated a vague objective ("Improve services to individuals with autism spectrum disorders and intellectual/developmental disabilities.”) in 13 different sections of the VR plan, with no differentiation of targeted strategies for outreach, service delivery, training, or collaboration.

VR practices can be categorized into two broad thematic areas: "organizational practices" which are system-level changes that foster innovative practices; and "promising service delivery practices" which facilitate employment outcomes at multiple levels across agencies and employers through use of partnerships, certification, and trainings (Del Valle et al., 2014; Leahy et al., 2014). Nearly all autism-related activities across state WIOA plans concerned service delivery practices. Organizational practices, such as efforts to change funding structures at the agency level, seemed generally limited to 'one-off' programs or waivers, versus representing an overall VR agency commitment to rewarding outcomes or incentivizing providers. The apparent lack of systems change efforts may be related to the cursory level of description within many WIOA plans or could be evidence of a lack of an overarching framework for improving autism-serving systems.

\subsection{State-level innovations in VR services for ASD}

As states have increased their efforts to improve employment for youth with disabilities, they are 
essentially becoming incubators for employment innovation. Researchers define innovation in the public sector as the implementation of a significant change to services and goods, operational processes, organizational methods, or the way an organization communicates with users, that has been implemented to better the outcomes of service users, which is new to the organization even if the innovation was developed by others (Arundel, Bloch, \& Ferguson, 2016; Bloch \& Bugge, 2013).

Six types of innovation in WIOA plans emerged: 1) comprehensive service models, such as Virginia's pilot project which combined technical assistance, supported employment, community support services, and therapeutic behavior services; 2) extension of longer-term vocational services via Medicaid waivers, such as the Pathways program in Delaware; 3) activities that focus on improving work environments - largely through a focus on supporting employers, such as Kentucky's training of its business teams; 4) reorganization of work staff by specialization, such as Texas' use of autism experts to train and support other staff; 5) novel funding models, such as Texas' enhanced reimbursement to autism providers and Georgia's attempts to develop a "braided milestone funding payment system"; and 6) a focus on developing standards of practice, such as Texas' attempts to define trainings required for providers. The first three are examples of improvements to services, while the last three are examples of organizational and process innovations. However, we found no innovations that focused on communication about the availability of VR services for individuals with autism or methods to influence uptake of VR services in this population.

Innovation is somewhat context dependent; what is innovative in one state might not be innovative in another and, therefore, might not be mentioned in a state plan. Further, it is highly possible that vocational innovation is occurring in states beyond what is evident in WIOA plans. For example, there is emerging evidence of successful use of Individual Placement and Support services, an evidence-based supported employment model for people with mental illness (McLaren, Lichtenstein, Lynch, Becker, \& Drake, 2017), for assisting young adults with ASD and co-occurring psychiatric disorders to achieve competitive employment. South Carolina is currently piloting this model (https://scdmh.net/individualplacement-and-support-ips/); although it was not mentioned in their state WIOA plan. Likewise, Maryland's Seamless Transition Collaborative (MSTC) has evidence of success in serving students with autism and other disabilities (Luecking, Fabian, Contreary, Honeycutt, \& Luecking, 2017), but is not mentioned in the state plan. As implementation of WIOA advances and more public funding is spent on Pre-ETS, states should develop mechanisms for identifying and evaluating vocational service innovations so that we can better learn from what is working or not working - at the community level to improve employment outcomes for people with autism (Shattuck \& Roux, 2014).

\subsection{Addressing the needs of transition-age youth with autism}

Our finding of frequent references to the vocational needs of TAY-ASD in state WIOA plans is supported by the finding that TAY-ASD currently comprise nearly $40 \%$ of all closed VR cases of youth with ID/DD (Roux, Rast, \& Shattuck, 2018), and that $11.8 \%$ of state VR agencies had at least one transition-specific program that targeted TAY-ASD in 2015 (Swankoski, Rosenbluth, \& Sevak, 2016). Nevertheless, while many autism-specific services identified in the WIOA plans did target youth, plans contained almost no information regarding how PreETS might be tailored to meet the needs of TAY-ASD. State progress in implementing Pre-ETS remains in an early stage and has been fraught with challenges and insufficient technical assistance (National Council on Disability, December 20, 2017). However, the almost complete lack of discussion of use of PreETS to meet the needs of underserved TAY-ASD is surprising given recent calls for VR to provide more opportunities and support for integrating education and employment (Office of Disability Employment Policy, September 16, 2014).

\subsection{Identified gaps in WIOA plan content}

Over half of all state plans identified an autismspecific training need and/or currently had a plan in place for providing training needed to better serve those with autism. Autism specialists typically delivered trainings, but the qualifications of these individuals were often not specified. Limited educational requirements for VR counselors may leave them underqualified to deliver counseling, while inservice training quality and topics vary from state to state (McClanahan \& Sligar, 2015). Guided practice and supervision are also important components of effective training for implementation of interventions 
(Beidas \& Kendall, 2010), but the extent of active versus passive learning opportunities was unclear in state plans.

Several states discussed the heterogeneity of vocational needs across the autism spectrum, but the breadth of proposed goals and strategies did not appear to reflect a variety of needs. For example, few plans addressed the vocational challenges posed by co-occurring mental health conditions. Harmuth and colleagues (2018) noted co-occurring conditions are rarely addressed in the employment literature concerning adults with ASD, an insight which appears to carry over into planning for delivery of VR services. There were more references in the WIOA plans to the VR needs of those with co-occurring visual impairment and autism than co-occurring mental health issues which are vastly higher in prevalence.

Only one state plan addressed cultural competence in regard to serving the autism population. This is problematic given known disparities in services and outcomes for people with autism from marginalized groups (Shattuck, Narendorf, et al., 2012; Shattuck, Wagner, Narendorf, Sterzing, \& Hensley, 2011). No outreach strategies were tailored to reaching African American, Hispanic, or low-income TAY or adults with autism. This mirrors a review of services and programs for adults with autism which found that services research was deficient in its consideration of the heterogeneity of the autism population (Shattuck, Roux, et al., 2012).

There was also a need for increased emphasis on developing relationships with employers via a 'dualcustomer approach' which views the employer as an equal target of VR intervention efforts (Haines et al., 2018). This approach is vital for building capacity, as the ability to provide job opportunities to match the range of skills and interests inherent in the autism spectrum is contingent upon having a wide variety of job opportunities available via partnerships with community employers.

Finally, there was little evidence in state plans regarding use of AT for those with autism, despite evidence that positive employment outcomes for people with autism can be promoted through the use of AT including iPad use for prompting and virtual reality simulations for interview training (Gentry, Kriner, Sima, McDonough, \& Wehman, 2015; Smith et al., 2015). AT can increase vocational independence/selfmanagement, but the purpose/use of AT specific to autism needs was often not clarified in the plans. However, further research is needed to determine which employment-related AT interventions are most effective and to inform how AT is best utilized within the VR service system.

\subsection{Limitations and future direction}

An inherent limitation of document analysis is potential for insufficient detail within documents which were not written for research purposes (Bowen, 2009). We may not have captured the full range of activities directed toward VR service users with autism. This analysis focused on autism-specific references, while goals and strategies in some state plans may have been directed toward broader groups of persons with ID/DD that included autism but did not provide autism-specific adaptations or focus. The limited scope of the study did not allow us to verify findings by interviewing states. Nor did we inquire as to how decisions were made regarding plan contents. Despite these limitations, we reduced bias by securing a complete set of documents representing all states and triangulating findings when possible.

A recent study identified 13 states with aboveaverage performance across indicators of VR services for TAY-ASD prior to WIOA implementation (Roux, Rast, Nye-Lengerman, et al., 2018). Future studies should continue to monitor state VR performance post-WIOA while gathering more complete contextual information about whether and how states are implementing autism-focused goals and strategies which may be contributing to better outcomes for TAY-ASD in some states. There is a corresponding need for study of local implementation of state employment policy (Butterworth, Christensen, \& Flippo, 2017), and study of the complex interplay between the local economics, physical environment (e.g., population density) and employment policy for people with disabilities, since state and local policies may have differential effects on subpopulations of people with disabilities (Sevak, O'Neill, Houtenville, \& Brucker, 2018).

\section{Conclusions}

Analyzing the content of WIOA state plans is an important step toward understanding disability policy aimed at facilitating employment for those on the autism spectrum and contributes to efforts to discover why individuals with autism in some states have better employment outcomes than in others. The IACC recently recognized "a particular gap in implementing and evaluating the coordination between policy 
and practice for the service needs of individuals with ASD (October 2017, p. 69).” The Employment First framework for systems change in the U.S. has also pushed for alignment of policy and practice to support the participation of people with disabilities in competitive, integrated employment (Office of Disability Employment Policy, n.d.). State WIOA plans contain evidence that states are beginning to recognize and document the vocational needs of the autism population and to consider ways to adapt delivery of VR services. The majority of states included some mention of autism within the VR portion of the WIOA state plan. However, autism-specific VR strategies, goals, and services appear to be the exception - not the norm, at least in terms of what is documented within WIOA state plans.

Given an overall lack of evidence-based vocational interventions, it is vital that states continue to innovate approaches to VR service delivery for autism (Shattuck \& Roux, 2014). Creation of practice-based evidence provides insights as to what works and doesn't work in service provision within the context of real-world factors. The directive to fund Pre-ETS programs, for example, has created an environment ripe for experimentation. However, focus must also be placed on documenting and measuring program design, implementation, and effectiveness, so that states can best allocate public dollars toward effective approaches to delivering vocational services for individuals with autism.

The process of developing and updating WIOA plans requires public input. Vigilance in reviewing state plans, providing feedback, and advocating for the inclusion of VR services specific to the needs of those with autism, is an essential activity for advocates and service providers alike. Oversight is important for ensuring that autism-related needs that are mentioned in the CSNA are then translated into WIOA state plans. Finally, plans should be monitored every four years for continued improvement and specificity in how autism is addressed, especially for states which identify autism as underserved.

\section{Acknowledgments}

This project was supported by the Health Resources and Services Administration (HRSA) of the U.S. Department of Health and Human Services (HHS) under UJ2MC31073: Maternal and Child Health-Autism Transitions Research Project. This information or content and conclusions are those of the author and should not be construed as the official position or policy of, nor should any endorsements be inferred by HRSA, HHS or the U.S. Government.

This project was also supported by funding from the Autism Science Foundation via an Accelerator Grant, under the title "Leveraging new federal law to improve employment outcomes for youth with autism."

\section{Conflict of interest}

The author(s) have no potential conflicts of interest to declare with respect to research, authorship, and or publication of this article.

\section{References}

American Psychiatric Association. (2013). Diagnostic and statistical manual of mental disorders (5th ed.). Washington, DC: Author.

Arundel, A., Bloch, C., \& Ferguson, B. (2016). Measuring innovation in the public sector. Hobart: Australian Innovation Research Centre, University of Tasmania.

Barbour, R. S. (2014). Quality of data analysis. In U. Frick (Ed.) The SAGE handbook of qualitative data analysis, (496-510). London: SAGE Publications Ltd.

Beidas, R. S., \& Kendall, P. C. (2010). Training therapists in evidence-based practice: A critical review of studies from a systems-contextual perspective. Clinical Psychology: Science and Practice, 17(1), 1-30.

Bird, K., Foster, M., \& Ganzglass, E. (2014). New opportunities to improve economic and career success for low-income youth and adults: Key provisions of the workforce innovation and opportunity act (WIOA). Washington, DC: Center for Law and Social Policy. Retrieved from www.clasp.org

Bloch, C., \& Bugge, M. M. (2013). Public sector innovationFrom theory to measurement. Structural Change and Economic Dynamics, 27, 133-145.

Bowen, G. A. (2009). Document analysis as a qualitative research method. Qualitative Research Journal, 9(2), 27-40.

Burgess, S., \& Cimera, R. E. (2014). Employment outcomes of transition-aged adults with autism spectrum disorders: A state of the states report. American Journal on Intellectual and Developmental Disabilities, 119(1), 64-83.

Butterworth, J., Christensen, J., \& Flippo, K. (2017). Partnerships in Employment: Building strong coalitions to facilitate systems change for youth and young adults. Journal of Vocational Rehabilitation, 47(3), 265-276.

Croen, L. A., Zerbo, O., Qian, Y., Massolo, M. L., Rich, S., Sidney, S., \& Kripke, C. (2015). The health status of adults on the autism spectrum. Autism, 19(7), 814-823.

Del Valle, R., Leahy, M. J., Sherman, S., Anderson, C. A., Tansey, T., \& Schoen, B. (2014). Promising best practices that lead to employment in vocational rehabilitation: Findings from a fourstate multiple case study. Journal of Vocational Rehabilitation, 41(2), 99-113. 
Gentry, T., Kriner, R., Sima, A., McDonough, J., \& Wehman, P. (2015). Reducing the need for personal supports among workers with autism using an iPod touch as an assistive technology: Delayed randomized control trial. Journal of Autism and Developmental Disorders, 45(3), 669-684.

Haines, K., Soldner, J. L., Zhang, L., Saint Laurent, M.-L., Knabe, B., West-Evans, K., . . \& \& Foley, S. (2018). Vocational rehabilitation and business relations: Preliminary indicators of state VR agency capacity. Journal of Vocational Rehabilitation, 48(1), 133-145.

Hall, A. C., Butterworth, J., Winsor, J., Gilmore, D., \& Metzel, D. (2007). Pushing the employment agenda: Case study research of high performing states in integrated employment. Intellectual and Developmental Disabilities, 45(3), 182-198.

Harmuth, E., Silletta, E., Bailey, A., Adams, T., Beck, C., \& Barbic, S. P. (2018). Barriers and facilitators to employment for adults with autism: A scoping review. Annals of International Occupational Therapy, 1(1), 31-40.

Hendricks, D. (2010). Employment and adults with autism spectrum disorders: Challenges and strategies for success. Journal of Vocational Rehabilitation, 32(2), 125-134.

Howlin, P., \& Moss, P. (2012). Adults with autism spectrum disorders. The Canadian Journal of Psychiatry, 57(5), 275-283.

Hurlbutt, K., \& Chalmers, L. (2004). Employment and adults with Asperger syndrome. Focus on Autism and other Developmental Disabilities, 19(4), 215-222.

IACC. (October 2017). 2016-2017 Interagency Autism Coordinating Committee Strategic Plan for Autism Spectrum Disorder. Retrieved from https://iacc.hhs.gov/publications/strategicplan/2017/

Kaya, C., Chan, F., Rumrill, P., Hartman, E., Wehman, P., Iwanaga, K.,...\& Avellone, L. (2016). Vocational rehabilitation services and competitive employment for transition-age youth with autism spectrum disorders. Journal of Vocational Rehabilitation, 45(1), 73-83.

LEAD Center. (February 2018). Reviewing and Updating Your WIOA Unified or Combined State Plan from a Disability Perspective. Washington, D.C: Office of Disability Employment Policy. Retrieved from www.leadcenter.org.

Leahy, M. J., Chan, F., Lui, J., Rosenthal, D., Tansey, T., Wehman, P.,...\& Menz, F. E. (2014). An analysis of evidence-based best practices in the public vocational rehabilitation program: Gaps, future directions, and recommended steps to move forward. Journal of Vocational Rehabilitation, 41(2), 147-163.

Livermore, G. A., \& Honeycutt, T. C. (2015). Employment and economic well-being of people with and without disabilities before and after the great recession. Journal of Disability Policy Studies, 26(2), 70-79.

Luecking, R. G., Fabian, E. S., Contreary, K., Honeycutt, T. C., \& Luecking, D. M. (2017). Vocational rehabilitation outcomes for students participating in a model transition program. Rehabilitation Counseling Bulletin, 61(3), 154-163.

Magiati, I., Tay, X. W., \& Howlin, P. (2014). Cognitive, language, social and behavioural outcomes in adults with autism spectrum disorders: A systematic review of longitudinal follow-up studies in adulthood. Clinical Psychology Review, 34(1), 7386.

Mann, D. R., \& Croake, S. (2018). Learning from State Vocational Rehabilitation Agencies on the eve of WIOA: State differences in service receipt and employment outcomes by applicant employment status. Journal of Vocational Rehabilitation, 48(3), 369-386.

McClanahan, M. L., \& Sligar, S. R. (2015). Adapting to WIOA 2014 minimum education requirements for vocational rehabilitation counselors. Journal of Rehabilitation, 81(3), 3-8.

McLaren, J., Lichtenstein, J. D., Lynch, D., Becker, D., \& Drake, R. (2017). Individual placement and support for people with autism spectrum disorders: A pilot program. Administration and Policy in Mental Health and Mental Health Services Research, 44(3), 365-373.

Migliore, A., Butterworth, J., \& Zalewska, A. (2014). Trends in vocational rehabilitation services and outcomes of youth with autism: 2006-2010. Rehabilitation Counseling Bulletin, 57(2), 80-89.

Müller, E., Schuler, A., Burton, B. A., \& Yates, G. B. (2003). Meeting the vocational support needs of individuals with Asperger syndrome and other autism spectrum disabilities. Journal of Vocational Rehabilitation, 18(3), 163-175.

National Council on Disability. (December 20, 2017). PreEmployment Transition Services Implementation by $V R$ Agencies and the Rehabilitaton Services Administration: The First 2.5 Years. Washington, D.C. Retrieved from ncd. gov/publications/2017/early-implementation-wioa-PETS.

Office of Disability Employment Policy. (n.d.). Employment First. Retrieved from www.dol.gov/odep/topics/Employment First.htm

Office of Disability Employment Policy. (September 16, 2014). Literature review of five federal systems serving transition age youth with disabilities. Retrieved from www.dol.gov/odep/pdf/20140916Literature.pdf.

Richards, J. (2012). Examining the exclusion of employees with Asperger syndrome from the workplace. Personnel Review, 41(5), 630-646.

Roux, A. M., Rast, J. E., Anderson, K. A., \& Shattuck, P. T. (2016). National autism indicators report: Vocational rehabilitation. Retrieved from Philadelphia, PA: https://drexel.edu/autismout comes/publications-and-reports/publications/National-Autism-Indicators-Report-Vocational-Rehabilitation/

Roux, A. M., Rast, J. E., Nye-Lengerman, K., Purtle, J., Lello, A., \& Shattuck, P. T. (2018). Identifying patterns of state vocational rehabilitation performance in serving transitionage youth on the autism spectrum. Autism in Adulthood. doi:10.1089/aut.2018.0018

Roux, A. M., Rast, J. E., \& Shattuck, P. T. (2019). State-level variation in vocational rehabilitation service use and related outcomes among transition-age youth on the autism spectrum. Journal of Autism and Developmental Disorders, 1(2). doi: 10.1007/s10803-018-3793-5

Schreier, M. (2012). Qualitative content analysis in practice: London: SAGE Publications Ltd.

Scott, M., Milbourn, B., Falkmer, M., Black, M., Bölte, S., Halladay, A.,. . \& \& Girdler, S. (2019). Factors impacting employment for people with autism spectrum disorder: A scoping review. Autism, 23(4). doi:1362361318787789

Sevak, P., O’Neill, J., Houtenville, A., \& Brucker, D. (2018). State and local determinants of employment outcomes among individuals with disabilities. Journal of Disability Policy Studies, 29(2), 119-128.

Shattuck, P. T., Narendorf, S. C., Cooper, B., Sterzing, P. R., Wagner, M., \& Taylor, J. L. (2012). Postsecondary education and 
employment among youth with an autism spectrum disorder. Pediatrics, 129(6), 1042-1049.

Shattuck, P. T., \& Roux, A. M. (2014). Autism: Moving toward an innovation and investment mindset. JAMA Pediatrics, 168(8), 698-699.

Shattuck, P. T., Roux, A. M., Hudson, L. E., Taylor, J. L., Maenner, M. J., \& Trani, J. F. (2012). Services for adults with an autism spectrum disorder. Canadian Journal of Psychiatry, 57(5), 284-291.

Shattuck, P. T., Wagner, M., Narendorf, S., Sterzing, P., \& Hensley, M. (2011). Post-high school service use among young adults with an autism spectrum disorder. Archives of Pediatric and Adolescent Medicine, 165(2), 141-146.

Smith, M. J., Fleming, M. F., Wright, M. A., Losh, M., Humm, L. B., Olsen, D., \& Bell, M. D. (2015). Brief report: Vocational outcomes for young adults with autism spectrum disorders at six months after virtual reality job interview training. Journal of Autism and Developmental Disorders, 45(10), 3364-3369.

Steinhausen, H. C., Mohr Jensen, C., \& Lauritsen, M. (2016). A systematic review and meta-analysis of the long-term overall outcome of autism spectrum disorders in adolescence and adulthood. Acta Psychiatrica Scandinavica, 133(6), 445-452.
Swankoski, K., Rosenbluth, S., \& Sevak, P. (2016). Supporting transition-aged youth after WIOA: A look at state vocational rehabilitation agencies. Retrieved from Rockville, MD: http:// vrpracticesandyouth.org/wp-content/uploads/2017/05/Study2 _IssueBrief_02.pdf

Turcotte, P., Mathew, M., Shea, L. L., Brusilovskiy, E., \& Nonnemacher, S. L. (2016). Service needs across the lifespan for individuals with autism. Journal of Autism and Developmental Disorders, 46(7), 2480-2489.

U.S. Department of Labor. (March 4, 2016). Training and Employment Guidance Letter WIOA. Washington D.C. Retrieved from https://wdr.doleta.gov/directives/attach/TEGL/tegl_14-15.pdf.

U.S. Government Accountability Office. (November 17, 2016). Youth with autism: Roundtable views of services needed during the transition into adulthood. (GAO-17-109). Retrieved from https://www.gao.gov/products/GAO-17-109.

The VR Needs Assessment Guide. (November 30, 2009). Washington, D.C. Retrieved from https://www2.ed.gov/programs/ rsabvrs/resources/vr-needs-assessment-guide-appendices.pdf.

Wei, X., Yu, J. W., Shattuck, P., McCracken, M., \& Blackorby, J. (2013). Science, technology, engineering, and mathematics (STEM) participation among college students with an autism spectrum disorder. Journal of Autism and Developmental Disorders, 43(7), 1539-1546. 